\title{
A Study on Seismic Response of an Irregular Structure with Different Angle of Incidence
}

\author{
Thanuja $\mathrm{D}^{1}$, Manohar $\mathrm{K}^{2}$
}

${ }^{1}$ Department of Civil Engineering, Sahyadri College of Engineering and Management, VTU University, Belagavi - 590018

${ }^{2}$ Assistant Professor, Department of Civil Engineering, Sahyadri College of Engineering and Management, VTU University, Belagavi - 590018

\begin{abstract}
Earthquakes are a natural calamity, feared by most and cause great destruction in and around the seismic zone where they occur. In seismic design of buildings, the earthquake motions are considered in principle directions of building which may not be true in all cases. The present study is focused on the earthquake incidence angle and its effect on the structure's column axial force and to obtain the critical angle using Non Linear Time History Analysis. A set of values from 0 to 90 degrees, with an increment of 10 degrees, have been used for angle of excitation. An asymmetrical structure of 10 storeys was considered. It can see that the critical angle may vary the column axial force from column to column. The models are analysed using ETABS 15 software. The structural parameters such as column axial force, displacement and story shear in columns are studied. The paper concludes that the internal forces of structural elements depend on the angle of incidence of seismic wave data. There are different critical angles for different parameters, not necessarily that it should be the same of the column axial force.
\end{abstract}

Keywords — Incidence angle, Non Linear Time History, Column axial force, Displacement, Story shear.

\section{INTRODUCTION}

Earthquakes are natural hazards under which disasters are mainly caused by damage to or collapse of buildings and other man-made structures. Experience has shown that for new constructions, establishing earthquake resistant regulations and their implementation is the critical safeguard against earthquake-induced damage. As regards existing structures, it is necessary to evaluate and strengthen them based on evaluation criteria before an earthquake. Earthquake damage depends on many parameters, including intensity, duration and frequency content of ground motion, geologic and soil condition, quality of construction, etc. Building design must be such as to ensure that the building has adequate strength, high ductility, and will remain as one unit, even while subjected to very large deformation. Sociologic factors are also important, such as density of population, time of day of the earthquake occurrence and community preparedness for the possibility of such an event. Up to now we can do little to diminish direct earthquake effects. However we can do much to reduce risks and thereby reduce disasters provided we design and build or strengthen the buildings so as to minimize the losses based on the knowledge of the earthquake performance of different building types during an earthquake. Observation of structural performance of buildings during an earthquake can clearly identify the strong and weak aspects of the design, as well as the desirable qualities of materials and techniques of construction, and site selection. The study of damage therefore provides an important step in the evolution of strengthening measures for different types of buildings.

\subsection{Earthquake Incidence Angle}

Earthquakes are well known for the damage and destruction that they leave behind. Present scenario demands the need for designing the structures to withstand seismic forces. In seismic design of structures, the earthquake motions are considered in principle directions of structure. Insalmostdall seismic design codes, consideration of simultaneous effects of two horizontal components of earthquake excitations is taken into account by applying $100 \%$ of earthquake lateral forces in the direction of one of the structure main axes and 30\% of those forces in the direction of other main axis. In reality the direction of the dominant component of excitations might not be one of the main directions of the structure axes and applying the main component in a direction other than main axes direction may lead to higher internal forces and stresses in the structure's 
structural elements. Therefore the structure should be resistant under different excitation angles of earthquake. Some researchers have worked on the effect of angle of excitation on the response values since mid-80s. Over the period of time, Time History Analysis has become an important tool is assessing the behavior of a structure subjected to seismic loads. Time History Analysis is a method by which earth motion input of a particular earthquake can be used to determine the response of the structure. The main advantage of using this method is that the accuracy of the system response is higher when compared to Response Spectrum analysis, as the actual earth motion record from an earthquake can be used to simulate the structure.

\section{METHODOLOGY}

\subsection{Project Details}

Multi-storeyed apartment, Safe bearing capacity of soil $(\mathrm{SBC})=300 \mathrm{KN} / \mathrm{mm} 2$, Height of each floor $=2.95 \mathrm{~m}$ (typical),Height of basement $=3.3 \mathrm{~m}$, Height of ground floor $=4.05 \mathrm{~m}$, Total height of the structure $=41.4 \mathrm{~m}$, Software $=$ E-Tabs, AutoCAD. The structure given is to be used for residential purpose. Basement + Earth+ 13 Upper Floors + Overhead Water tank. The height of the basement and earth floor is $3.3 \mathrm{~m}$ and typical floor height is $2.95 \mathrm{~m}$. Total height of the structure is $41.1 \mathrm{~m}$ above the plinth and each floor of the structure comprises of six houses, where four of them have one Living room, one Master Bedroom and two other Bedrooms with three toilets, one foyer, one Kitchen and one Dining room, one balcony and one utility and two of them have one Living room, one Master Bedroom and one Bedroom with two toilets, one foyer, one Kitchen and one Dining room, one balcony and one utility.

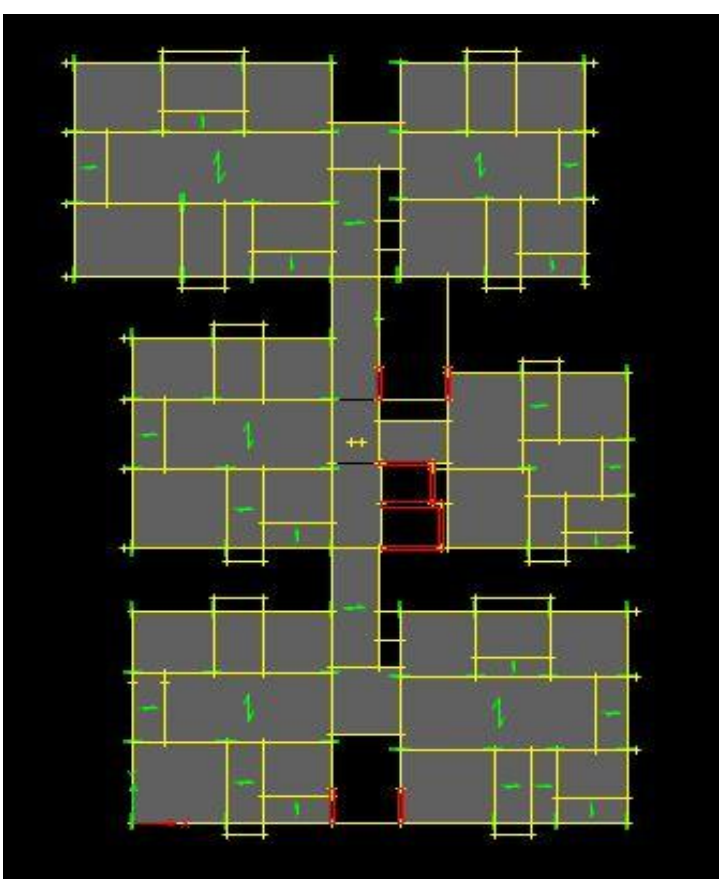

FIG. 1: E-TABS MODEL- PLAN

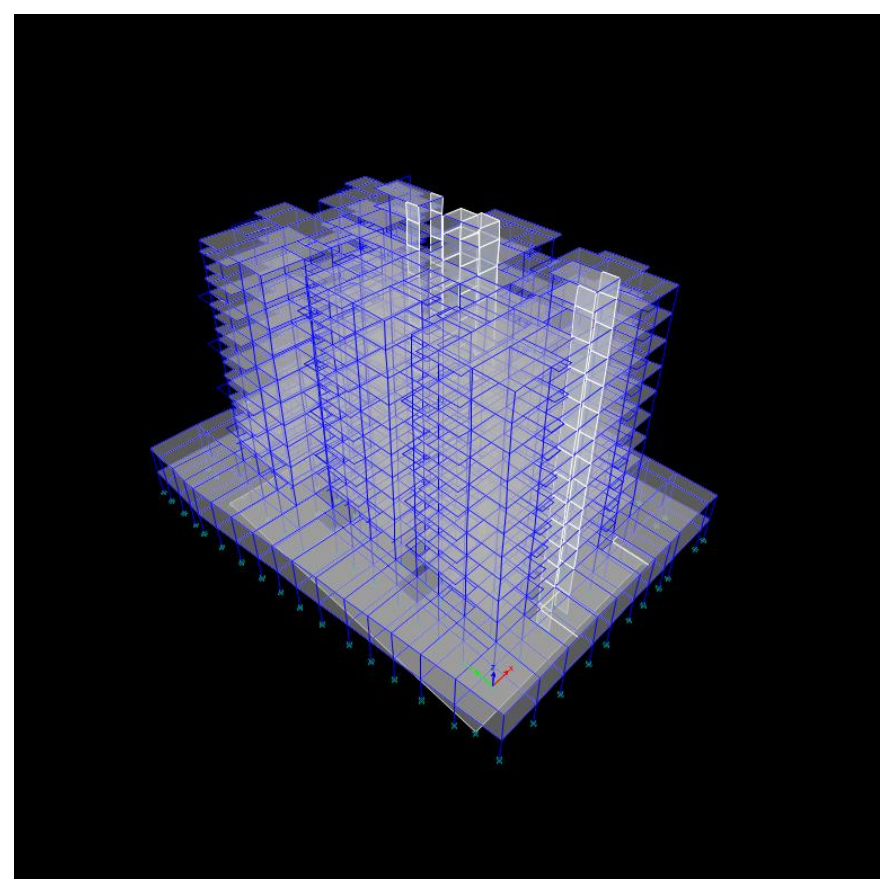

FIG. 2: E-TABS MODEL- 3D

\section{RESULTS AND DISCUSSION}

The results of Time History Analysis in the form of maximum column forces, column moments, maximum displacement and storey shear were studied.

\subsection{Maximum Column Forces}

The values of maximum column forces and the variation with incidence angle is shown in Table 1.The max column force was found to be $-3693.42 \mathrm{kN}$ for the load combination 1.5(TDL-ELX-0.3ELY) Max for column C-20 at the basement-1at $70^{0}$ angle. 
TABLE 4.1

COLUMN FORCES FOR ALL THE ANGLE OF INCIDENCE $\left(0^{\circ}-90^{\circ}\right)$

\begin{tabular}{|c|c|c|c|c|c|}
\hline \multirow{2}{*}{ Story } & \multirow{2}{*}{ Column } & \multirow{2}{*}{ Unique Name } & \multirow{2}{*}{ Load Case/Combo } & $\mathbf{P}$ & Angle \\
\hline & & & & $\mathbf{k N}$ & Deg. \\
\hline Basement-1 & $\mathrm{C} 20$ & 2578 & 0.9TDL+1.5(0.3THX-THY) Min & -2217.3 & 0 \\
\hline Basement-1 & $\mathrm{C} 20$ & 2578 & 1.2(TLD+LL+0.3THX-TY) Min & -3232.67 & 0 \\
\hline Basement-1 & $\mathrm{C} 20$ & 2578 & 1.5(TDL+0.3EX-EY) Min & -3693.38 & 0 \\
\hline Basement-1 & $\mathrm{C} 20$ & 2578 & 0.9TDL+1.5(0.3THX-THY) Min & -2217.35 & 10 \\
\hline Basement-1 & $\mathrm{C} 20$ & 2578 & 1.2(TLD+LL+0.3THX-TY) Min & -3232.7 & 10 \\
\hline Basement-1 & $\mathrm{C} 20$ & 2578 & 1.5(TDL+0.3EX-EY) Min & -3693.42 & 10 \\
\hline Pocomont 1 & $C 20$ & 2570 & 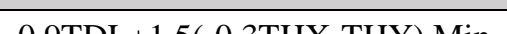 & 221722 & 20 \\
\hline Basement-1 & $\mathrm{C} 20$ & 2578 & 1 2(TLD+LL-0 3THX-TY) Min & -3232.69 & 20 \\
\hline Basement-1 & $\mathrm{C} 20$ & 2578 & 1.5(TDL-0.3EX-EY) Min & -3693.41 & 20 \\
\hline Basement-1 & $\mathrm{C} 20$ & 2578 & 0 9TDL+1 5(-03THX-THY) Min & -221724 & 30 \\
\hline Basement-1 & $\mathrm{C} 20$ & 2578 & 1.2(TLD+LL-0.3THX-TY) Min & -3232.62 & 30 \\
\hline Basement-1 & $\mathrm{C} 20$ & 2578 & 1.5(TDL-0.3EX-EY) Min & -3693.32 & 30 \\
\hline Basement-1 & $\mathrm{C} 20$ & 2578 & 0.9 TDL+1.5(-0.3THX-THY) Min & -2217.05 & 40 \\
\hline Basement-1 & $\mathrm{C} 20$ & 2578 & 1.2(TLD+LL-0.3THX-TY) Min & -3232.47 & 40 \\
\hline Basement-1 & $\mathrm{C} 20$ & 2578 & 1.5(TDL-0.3EX-EY) Min & -3693.13 & 40 \\
\hline Basement-1 & $\mathrm{C} 20$ & 2578 & 0.9 TDL+1.5(-THX-0.3THY) Min & -2217.11 & 50 \\
\hline Basement-1 & $\mathrm{C} 20$ & 2578 & 1.2(TLD+LL-THX-0.3TY) Min & -3232.51 & 50 \\
\hline Basement-1 & $\mathrm{C} 20$ & 2578 & 1.5(TDL-0.3EX-EY) Min & -3692.85 & 50 \\
\hline Basement-1 & $\mathrm{C} 20$ & 2578 & $0.9 \mathrm{TDL}+1.5(-\mathrm{THX}-0.3 \mathrm{THY}) \mathrm{Min}$ & -2217.27 & 60 \\
\hline Basement-1 & $\mathrm{C} 20$ & 2578 & 1.2(TLD+LL-THX-0.3TY) Min & -3232.64 & 60 \\
\hline Basement-1 & $\mathrm{C} 20$ & 2578 & 1.5(TDL-EX-0.3EY) Min & -3693.35 & 60 \\
\hline Basement-1 & $\mathrm{C} 20$ & 2578 & 0.9 TDL+1.5(-THX-0.3THY) Min & -2217.34 & 70 \\
\hline Basement-1 & $\mathrm{C} 20$ & 2578 & 1.2(TLD+LL-THX-0.3TY) Min & -3232.7 & 70 \\
\hline Basement-1 & $\mathrm{C} 20$ & 2578 & 1.5(TDL-EX-0.3EY) Min & -3693.42 & 70 \\
\hline Basement-1 & $\mathrm{C} 20$ & 2578 & $0.9 \mathrm{TDL}+1.5(-\mathrm{THX}+0.3 \mathrm{THY}) \mathrm{Min}$ & -2217.37 & 80 \\
\hline Basement-1 & $\mathrm{C} 20$ & 2578 & 1.2(TLD+LL-THX+0.3TY) Min & -3232.72 & 80 \\
\hline Basement-1 & $\mathrm{C} 20$ & 2578 & 1.5(TDL-0.3EX+EY) Min & -3691.77 & 80 \\
\hline Basement-1 & $\mathrm{C} 20$ & 2578 & 0.9TDL+1.5(-THX-0.3THY) Min & -2217.3 & 90 \\
\hline Basement-1 & $\mathrm{C} 20$ & 2578 & 1.2(TLD+LL-THX-0.3TY) Min & -3232.67 & 90 \\
\hline Basement-1 & $\mathrm{C} 20$ & 2578 & 1.5(TDL-EX-0.3EY) Min & -3693.38 & 90 \\
\hline
\end{tabular}




\subsection{Maximum Column Moments}

The values of maximum column moments and the variation with incidence angle is shown in Table 2. The maximum moment was in 1ST FLOOR for the column C-32 with the load combination 1.2(TLD+LL-0.3THX+TY) Max of 225.3083 $\mathrm{kN}-\mathrm{m}$ for an incidence angle of $80^{\circ}$.

TABLE 2

COLUMN MOMENTS FOR ALL THE ANGLE OF INCIDENCE $\left(0^{\circ}-90^{\circ}\right)$

\begin{tabular}{|c|c|c|c|c|c|}
\hline \multirow{2}{*}{ Story } & \multirow{2}{*}{ Column } & \multirow{2}{*}{ Load Case/Combo } & $\mathbf{P}$ & M3 & Angle \\
\hline & & & $\mathbf{k N}$ & kN-m & Deg. \\
\hline Ground floor & $\mathrm{C} 32$ & 0.9TDL+1.5(THX-0.3THY) Min & -1621.179 & -95.8313 & 0 \\
\hline 1st Floor & $\mathrm{C} 32$ & 1.2(TLD+LL-THX+0.3TY) Max & -2028.8649 & 225.2589 & 0 \\
\hline Ground floor & $\mathrm{C} 32$ & 1.5(TDL+EX+0.3EY) Min & -2696.5294 & -159.1 & 0 \\
\hline Ground floor & $\mathrm{C} 32$ & $0.9 \mathrm{TDL}+1.5$ (THX-0.3THY) Min & -1621.3585 & -95.8373 & 10 \\
\hline 1st Floor & $\mathrm{C} 32$ & 1.2(TLD+LL-THX+0.3TY) Max & -2028.8187 & 225.2588 & 10 \\
\hline Ground floor & $\mathrm{C} 32$ & 1.5(TDL+EX+0.3EY) Min & -2696.6017 & -159.108 & 10 \\
\hline & & & & & \\
\hline Ground floor & $\mathrm{C} 32$ & $0.9 \mathrm{TDL}+1.5(\mathrm{THX}+0.3 \mathrm{THY}) \mathrm{Min}$ & -1621.3182 & -95.8335 & 20 \\
\hline 1st Floor & $\mathrm{C} 32$ & 1.2(TLD+LL-THX+0.3TY) Max & -2028.913 & 225.2804 & 20 \\
\hline 1st Floor & $\mathrm{C} 32$ & 1.5(TDL-EX+0.3EY) Max & -2211.2698 & 150.3738 & 20 \\
\hline Ground floor & $\mathrm{C} 32$ & $0.9 \mathrm{TDL}+1.5(\mathrm{THX}+0.3 \mathrm{THY}) \mathrm{Min}$ & -1621.2853 & -95.8191 & 30 \\
\hline 1st Floor & $\mathrm{C} 32$ & $1.2(\mathrm{TLD}+\mathrm{LL}-\mathrm{THX}+0.3 \mathrm{TY}) \mathrm{Max}$ & -2028.8427 & 225.2352 & 30 \\
\hline Ground floor & C167 & 1.5(TDL-EX+0.3EY) Min & -469.6913 & -239.32 & 30 \\
\hline Ground floor & $\Gamma 32$ & 0 9TDI +1 5(THX+0 3THY) Min & -16210826 & -957812 & 40 \\
\hline 1st Floor & $\mathrm{C} 32$ & $1.2(\mathrm{TLD}+\mathrm{LL}-\mathrm{THX}+0.3 \mathrm{TY}) \mathrm{Max}$ & -2028.9545 & 225.1234 & 40 \\
\hline Basement-1 & $\mathrm{C} 32$ & 1.5(TDL-0.3EX-EY) Min & -2966.8733 & -70.2712 & 40 \\
\hline & & & & & \\
\hline Ground floor & $\mathrm{C} 32$ & $0.9 \mathrm{TDL}+1.5(\mathrm{THX}+0.3 \mathrm{THY}) \mathrm{Min}$ & -1620.7625 & -95.7169 & 50 \\
\hline 1st Floor & $\mathrm{C} 32$ & 1.2(TLD+LL-0.3THX+TY) Max & -2029.8786 & 225.0561 & 50 \\
\hline Basement-1 & $\mathrm{C} 32$ & 1.5(TDL-0.3EX-EY) Min & -2967.814 & -70.4311 & 50 \\
\hline Ground floor & $\mathrm{C} 32$ & 0.9TDL+1.5(-0.3THX-THY) Min & -1619.9548 & -95.7232 & 60 \\
\hline 1st Floor & $\mathrm{C} 32$ & 1.2(TLD+LL-0.3THX+TY) Max & -2029.4102 & 225.2217 & 60 \\
\hline Basement-1 & $\mathrm{C} 32$ & 1.5(TDL-0.3EX-EY) Min & -2968.5768 & -70.5425 & 60 \\
\hline 1st Floor & $\mathrm{C} 32$ & $0.9 \mathrm{TDL}+1.5(-0.3 \mathrm{THX}+\mathrm{THY}) \mathrm{Max}$ & -1324.0325 & 91.6141 & 70 \\
\hline 1st Floor & $\mathrm{C} 32$ & 1.2(TLD+LL-0.3THX+TY) Max & -2029.1073 & 225.3066 & 70 \\
\hline Ground floor & $\mathrm{C} 32$ & 1.5(TDL+0.3EX-EY) Min & -2696.2622 & -159.065 & 70 \\
\hline 1st Floor & $\mathrm{C} 32$ & 0.9TDL+1.5(-0.3THX+THY) Max & -1323.8518 & 91.6161 & 80 \\
\hline 1st Floor & $\mathrm{C} 32$ & 1.2(TLD+LL-0.3THX+TY) Max & -2028.9627 & 225.3083 & 80 \\
\hline Ground floor & $\mathrm{C} 32$ & 1.5(TDL+0.3EX-EY) Min & -2696.497 & -159.082 & 80 \\
\hline Ground floor & $\mathrm{C} 32$ & 0.9 TDL+1.5(0.3THX-THY) Min & -1621.1683 & -95.8352 & 90 \\
\hline 1st Floor & $\mathrm{C} 32$ & 1.2(TLD+LL+0.3THX+TY) Max & -2028.8649 & 225.2589 & 90 \\
\hline Ground floor & $\mathrm{C} 32$ & 1.5(TDL+0.3EX-EY) Min & -2696.5294 & -159.1 & 90 \\
\hline
\end{tabular}




\subsection{Maximum Story Displacement}

The values of maximum story displacement and the Comparison between displacements for different angles is shown in Figure 3 and Table 3.Displacement is more in $40^{\circ}$ in $\mathrm{x}$-direction $5.47 \mathrm{~mm}$ and $20^{\circ}$ in y-direction $2.73 \mathrm{~mm}$ for the combo 1.5(TDL+0.3EX-EY).

TABLE 3

COMPARISON BETWEEN DISPLACEMENTS FOR DIFFERENT ANGLES

\begin{tabular}{|c|c|c|}
\hline Angle & $\mathbf{X}$ direction $(\mathbf{m m})$ & Y direction( $\mathbf{m m})$ \\
\hline 10 & 2.58 & 5.63 \\
\hline 20 & 2.73 & 5.76 \\
\hline 30 & 2.84 & 5.47 \\
\hline 40 & 2.96 & 5.47 \\
\hline 50 & 2.81 & 5.39 \\
\hline 60 & 2.7 & 5.49 \\
\hline 70 & 2.5 & 5.53 \\
\hline 80 & 2.56 & 5.54 \\
\hline 90 & 2.503 & 5.526 \\
\hline
\end{tabular}

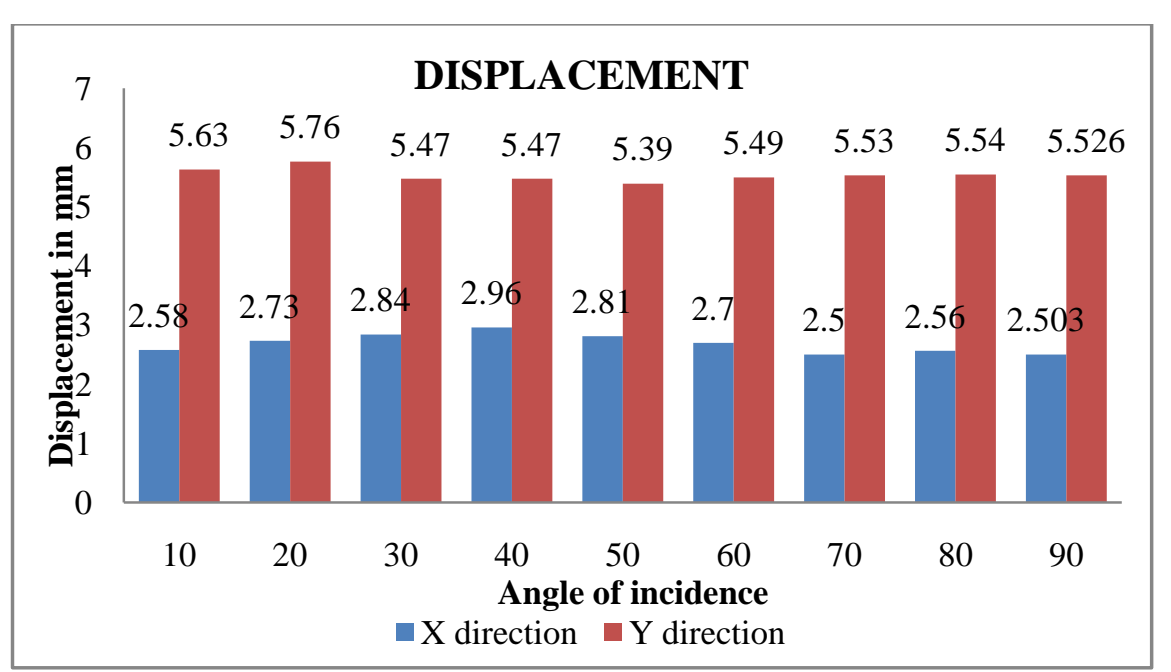

FIGURE 3: COMPARISON BETWEEN DISPLACEMENTS FOR DIFFERENT ANGLES

\subsection{Maximum Story Shear}

The values of maximum story shear and the Comparison between story shear for different angles is shown in Figure 4 and Table 4. Story shear is more in $70^{\circ}$ with $128 \mathrm{kN}$ in $\mathrm{x}$-direction and $50^{\circ}$ with $105 \mathrm{kN}$ in y-direction for the combo 1.5(TDL+0.3EX-EY).

TABLE 4

COMPARISON BETWEEN STORY SHEAR FOR DIFFERENT ANGLES

\begin{tabular}{|c|c|c|}
\hline Angle & $\mathbf{X}$ direction(kN) & Y direction $(\mathbf{k N})$ \\
\hline 10 & 128 & 57 \\
\hline 20 & 127 & 73 \\
\hline 30 & 123.6 & 87 \\
\hline 40 & 115 & 101 \\
\hline 50 & 120 & 105 \\
\hline 60 & 126 & 93 \\
\hline 70 & 128 & 78 \\
\hline 80 & 126 & 61 \\
\hline 90 & 126 & 46 \\
\hline
\end{tabular}




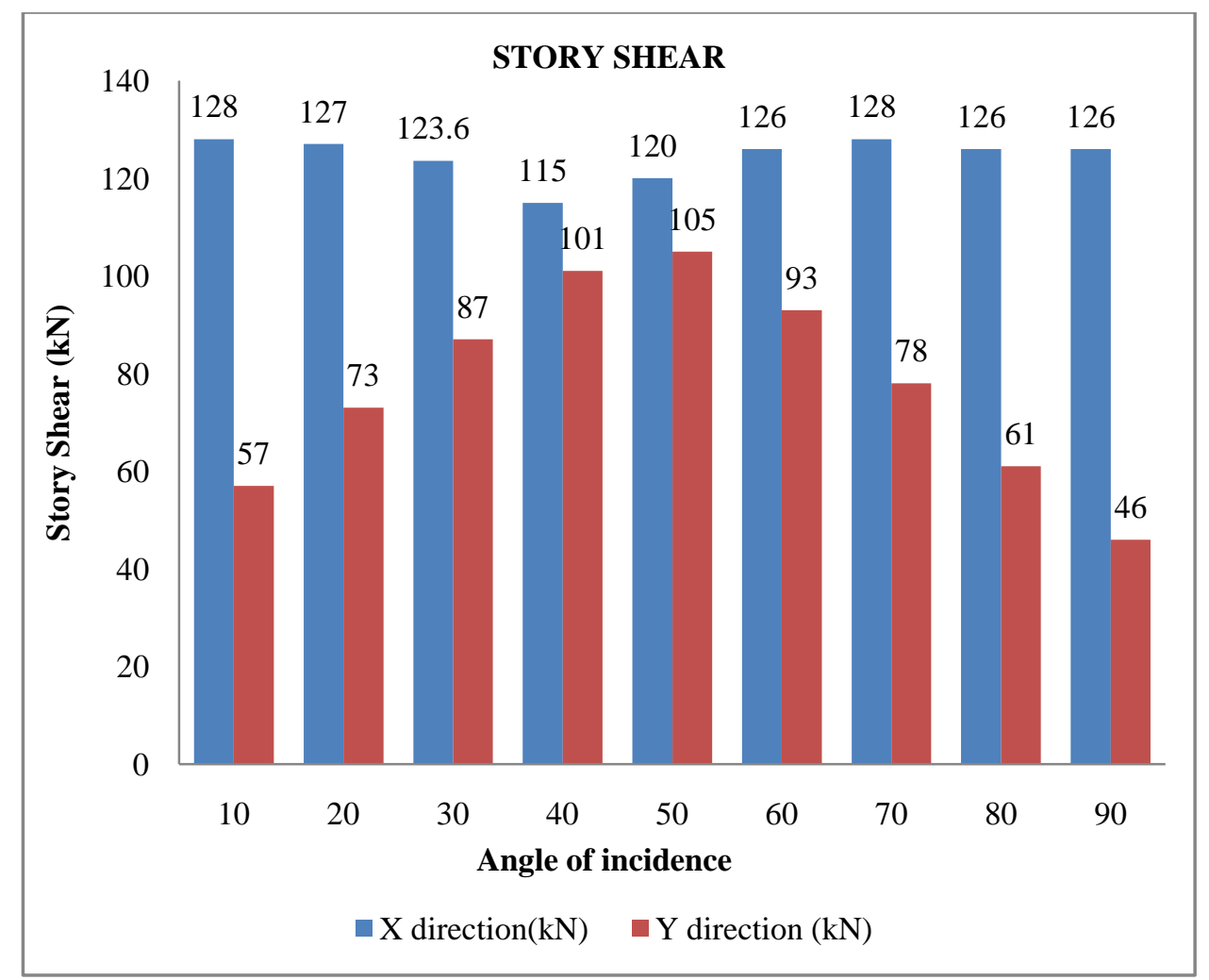

FIGURE 4: COMPARISON BETWEEN STORY SHEAR FOR DIFFERENT ANGLES

\section{CONCLUSION}

- The internal forces of structural elements depend on the angle of incidence of seismic wave data.

- There are different critical angles for different parameters, not necessarily that it should be the same of the column axial force.

- The maximum displacement and maximum column axial forces are of same angle i.e. $70^{\circ}$ for EL CENTRO earthquake data.

- The critical angle depends on the geometry of the structure.

- The objective of this study is to highlight that, the earthquake motions are considered in principle directions of structure but excitations might not be in one of the main directions of the structure axes.

\section{REFERENCES}

[1] Bhatnagar U. "Seismic performance on skewed bridges under orthogonal earth motion components" Journal of Structural Engineering, 2013, pp.1-94.

[2] Salemi, M. H. "Studying the Effect of Earthquake Excitation Angle on the Internal Forces of Steel Structures Elements by Using Non Linear Time History Analysis". 14th World Conference on Earthquake Engineering, 2008, pp.1-8.

[3] Poursha, F. K.'Responses of Three Dimensional Structures under Bidirectional and Unidirectional Seismic Excitations". 13th World Conference on Earthquake Engineering, 2004, No 55.

[4] M. Sri Kanya, "Effect of Earthquake Incidence Angle on Seismic Performance of RC Buildings". International Journal of Research in Engineering and Technology, vol 4, Issue 13, 2006, pp.156-161.

[5] M. Sri Kanya, (2006) "Effect of Earthquake Incidence Angle on Seismic Performance of RC Buildings". International Journal of Research in Engineering and Technology, vol 4, Issue 13, pp.156-161. 